\title{
Microsurgical anatomy of the arterial basket of the conus medullaris
}

\author{
Nikolay L. Martirosyan, MD, ${ }^{1,2}$ M. Yashar S. Kalani, MD, PhD, ${ }^{1}$ G. Michael Lemole Jr., MD, ${ }^{2}$ \\ Robert F. Spetzler, MD, ${ }^{1}$ Mark C. Preul, MD, ${ }^{1}$ and Nicholas Theodore, MD ${ }^{1}$ \\ 'Division of Neurological Surgery, Barrow Neurological Institute, St. Joseph's Hospital and Medical Center, Phoenix; \\ and ${ }^{2}$ Division of Neurological Surgery, University of Arizona, Tucson, Arizona
}

\begin{abstract}
OBJECT The arterial basket of the conus medullaris (ABCM) consists of 1 or 2 arteries arising from the anterior spinal artery (ASA) and circumferentially connecting the ASA and the posterior spinal arteries (PSAs). The arterial basket can be involved in arteriovenous fistulas and arteriovenous malformations of the conus. In this article, the authors describe the microsurgical anatomy of the $\mathrm{ABCM}$ with emphasis on its morphometric parameters and important role in the intrinsic blood supply of the conus medullaris.
\end{abstract}

METHODS The authors performed microsurgical dissections on 16 formalin-fixed human spinal cords harvested within 24 hours of death. The course, diameter, and branching angles of the arteries comprising the ABCM were then identified and measured. In addition, histological sections were obtained to identify perforating vessels arising from the ABCM.

RESULTS The ASA tapers as it nears the conus medullaris (mean preconus diameter $0.7 \pm 0.12 \mathrm{~mm}$ vs mean conus diameter $0.38 \pm 0.08 \mathrm{~mm}$ ). The ASA forms an anastomotic basket with the posterior spinal artery (PSA) via anastomotic branches. In most of the specimens $(n=13,81.3 \%)$, bilateral arteries formed connections between the ASA and PSA. However, in the remaining specimens $(n=3,18.7 \%)$, a unilateral right-sided anastomotic artery was identified. The mean diameter of the right $A B C M$ branch was $0.49 \pm 0.13 \mathrm{~mm}$, and the mean diameter of the left branch was $0.53 \pm 0.14 \mathrm{~mm}$. The mean branching angles of the arteries forming the anastomotic basket were $95.9^{\circ} \pm 36.6^{\circ}$ and $90^{\circ} \pm 34.3^{\circ}$ for the right- and left-sided arteries, respectively. In cases of bilateral arterial anastomoses between the ASA and PSA, the mean distance between the origins of the arteries was $4.5 \pm 3.3 \mathrm{~mm}$. Histological analysis revealed numerous perforating vessels supplying tissue of the conus medullaris.

CONCLUSIONS The ABCM is a critical anastomotic connection between the ASA and PSA, which play an important role in the intrinsic blood supply of the conus medullaris. The ABCM provides an important compensatory function in the blood supply of the spinal cord. Its involvement in conus medullaris vascular malformations makes it a critical anatomical structure.

http://thejns.org/doi/abs/10.3171/2014.10.SPINE131081

KEY WORDS conus medullaris; arterial basket; anterior spinal artery; posterior spinal artery; microsurgical anatomy

$\mathrm{D}$ URING embryonic development, the vascular supply of the spinal cord undergoes significant modification and pruning. The differential growth of the spinal cord and spinal column results in the descent of the spinal nerve roots and ascent of the spinal cord into its adult configuration by the 1 st year of life. ${ }^{4}$ The blood supply to the spinal cord consists of an anterior spinal artery (ASA) and paired smaller posterior spinal arteries (PSAs). ${ }^{17,22,23}$ The arterial blood supply to the spinal cord consists of several anastomoses that allow for redundancy of supply to the spinal cord. ${ }^{15,17,22-24}$ One critical anasto- motic connection is the arterial basket of the conus medullaris (ABCM). Initially described by Adamkiewicz in the 1880 s, it has subsequently been studied using angiography by Djindjian and Lasjaunias. ${ }^{1,25-7,13,14,16}$

The ABCM consists of 1 or 2 arterial branches connecting the ASA and PSAs at the level of the conus medullaris. Although initially thought of as a fail-safe mechanism for providing alternative vascular supply to the conus, the ABCM has also been noted to be a critical component of vascular malformations of the conus medullaris. ${ }^{6,18,21}$ To the best of our knowledge, this is the first detailed micro-

ABBREVIATIONS ABCM = arterial basket of the conus medullaris; $A S A=$ anterior spinal artery; $A V M=$ arteriovenous malformation; $P S A=$ posterior spinal artery.

SUBMITTED November 26, 2013. ACCEPTED October 14, 2014.

INCLUDE WHEN CITING Published online March 6, 2015; DOI: 10.3171/2014.10.SPINE131081.

DISCLOSURE This work was supported by a grant from the Newsome Endowment in Neurosurgery Research held by Dr. Preul and from a Barrow Neurological Founda-

tion grant to Dr. Martirosyan. 
surgical anatomical study of the ABCM with emphasis on the morphometric characteristics and branching pattern of the arteries forming the anastomosis between the ASA and PSAs.

\section{Methods \\ Study Material}

We used 16 human cadaveric thoracolumbar spines up to 24 hours postmortem with no known vascular disease of the spinal cord. The anterior corpectomies and foraminotomies were performed utilizing a high-speed drill and rongeurs. The ventral aspect of the entire thoracolumbar spinal thecal sac and nerve root were fully exposed. Utilizing an operating microscope, a longitudinal midline durotomy was performed and the ventral spinal cord and cauda equina were defined. The artery of Adamkiewicz was identified and cannulated with a 32-gauge plastic cannula. Continuous room-temperature normal saline irrigation was used to purge the vascular system until no gross blood clots could be observed in vessels. Next, a red-colored silicone-rubber mixture was injected into the artery of Adamkiewicz. ${ }^{3}$ This injection was performed under moderate pressure to avoid contrast extravasation and ensure adequate latex filling into distal small caliber vessels. Macroscopically, there was no evidence of vascular malformations or pathology involving the spinal cords (including atherosclerosis that could alter the latex injection). The specimens were fixed in a 5\% formalin solution. One week after formalin fixation, we performed microsurgical dissection of the samples. ${ }^{6,18}$ We identified and measured the course, diameter, and branching angle of the arteries comprising the ABCM. After all measurements were obtained, spinal cords sections were sent for histological analysis to identify smaller caliber perforating vessels arising from the ABCM.

\section{Histological Analysis \\ Embedding and Sectioning}

Spinal cords were treated with $20 \%$ glycerol and $2 \%$ dimethylsulfoxide to prevent freeze artifacts. Spinal cords were embedded in a gelatin matrix using MultiCord Technology (NeuroScience Associates) as used in previous studies. ${ }^{8} 19$ The block of embedded spinal cord was allowed to cure and was then rapidly frozen by immersion in isopentane chilled with crushed dry ice. The block was mounted on a freezing stage of an AO 860 sliding microtome and sectioned in the coronal and sagittal plane at 40 $\mu \mathrm{m}$. All sections cut were collected sequentially into a 4 $\times 6$ array of containers. These containers were filled with Antigen Preserve solution (50\% phosphate-buffered saline [pH 7.0], 50\% ethylene glycol, and $1 \%$ polyvinyl pyrrolidone) for sections to be stained immunohistochemically. At the completion of sectioning, each container held a serial set of 1 of every 24th section (or, 1 section every 960 $\mu \mathrm{m})$. Each of the large sections cut from the block was actually a composite section holding individual sections from the spinal cord embedded in each block. With such composite sections, uniformity of staining was achieved.

Nissl (Thionine) Stain

Every sixth section (every $240 \mu \mathrm{m}$ ) was used for stain- ing. For Nissl staining, 40- $\mu \mathrm{m}$ sections were first mounted onto gelatinized slides. They were then dehydrated through alcohol rinses prior to defatting in a chloroform/ ether/alcohol solution. The slides were then rehydrated and stained in $0.05 \%$ thionine $/ 0.08 \mathrm{M}$ acetate buffer, at a $\mathrm{pH}$ of 4.5. Following deionized water rinses, the slides were differentiated in 95\% alcohol/acetic acid and dehydrated in a standard alcohol series, cleared in xylene, and coverslipped.

\section{Results \\ Characteristics of the ABCM}

The ASA tapers distally at the level of the conus medullaris. The mean preconus diameter of the ASA measured $0.7 \pm 0.12 \mathrm{~mm}$. At the level of the conus, the mean diameter of the artery narrowed to $0.38 \pm 0.08 \mathrm{~mm}$. The ASA forms an anastomotic basket with the PSA via 1 or 2 anastomotic branches (see Table 1 for measurements). In most specimens $(\mathrm{n}=13,81.3 \%)$, we identified 2 anastomotic branches connecting the ASA and PSA (Fig. 1). In the remaining specimens $(n=3,18.7 \%)$, a unilateral right-sided anastomotic artery was identified (Fig. 2D). We measured the diameter of the anastomotic arteries in all specimens. The mean diameter of the right anastomotic branch was $0.49 \pm 0.13 \mathrm{~mm}$, and the mean diameter of the left anastomotic branch was $0.53 \pm 0.14 \mathrm{~mm}$. The branching angle of the arteries forming the anastomotic basket was $95.9^{\circ}$ $\pm 36.6^{\circ}$ on the right side, and $90^{\circ} \pm 34.3^{\circ}$ on the left side.

\section{Branching Orientation and Anastomosis Between the ASA and PSA}

In most specimens, the arterial basket connecting the ASA and PSA consisted of 2 arterial connection points. In these instances, we noted that in 6 cases the right vessel branched first (Fig. 2A), in 5 cases the left vessel branched first (Fig. 2B), and in 2 cases both vessels branched simultaneously (Fig. 2C). These 3 differing branching orientations constitute the spectrum of patterns noted in the ABCM. In cases of bilateral arterial anastomoses between the ASA and PSA, the mean distance between the origins of the arteries was $4.5 \pm 3.3 \mathrm{~mm}$.

\section{Histological Results}

We were able to identify small caliber $(<0.5 \mathrm{~mm})$ centripetal perforating branches arising from the ABCM (Fig. 3 ). Due to limitations of histological sections, we were not able to identify precisely the number of these branches and their lengths.

\section{Discussion}

\section{Anastomotic Contribution of the $\mathrm{ABCM}$}

The ABCM functions as an anastomotic connection between the ASA and PSA. The arterial basket was symmetric in most specimens $(n=13)$, meaning that the ASA was connected to paired PSAs via right and left branches. This symmetric configuration allows for continuity of circulation between the anterior and posterior spinal circulations. In rare cases $(n=3)$, the anastomotic network was asymmetrical with a dominant artery connecting the ASA to one of the PSAs. This rare arrangement resulted in 1 
TABLE 1. Morphometric parameters of ABCM branches

\begin{tabular}{|c|c|c|c|c|c|c|c|}
\hline $\begin{array}{l}\text { Spinal Cord } \\
\text { No. }\end{array}$ & $\begin{array}{l}\text { ASA Above } \\
\text { Origin (mm) }\end{array}$ & $\begin{array}{l}\text { ASA Below } \\
\text { Origin }(\mathrm{mm})\end{array}$ & $\begin{array}{l}\text { Right Branch } \\
\qquad(\mathrm{mm})\end{array}$ & Right Angle $\left({ }^{\circ}\right)$ & Left Branch (mm) & Left Angle $\left({ }^{\circ}\right)$ & $\begin{array}{c}\text { Distance Between } \\
\text { Origins }(\mathrm{mm})\end{array}$ \\
\hline 1 & 0.8 & 0.3 & 0.4 & 120 & 0.5 & 85 & 2 \\
\hline 2 & 0.5 & 0.4 & 0.4 & 115 & NA & NA & NA \\
\hline 3 & 0.6 & 0.4 & 0.15 & 100 & 0.25 & 130 & 6.4 \\
\hline 4 & 0.75 & 0.5 & 0.5 & 85 & 0.45 & 120 & 6.1 \\
\hline 5 & 0.55 & 0.35 & 0.5 & 160 & NA & NA & NA \\
\hline 6 & 0.55 & 0.4 & 0.5 & 50 & NA & NA & NA \\
\hline 7 & 0.75 & 0.3 & 0.6 & 90 & 0.5 & 85 & 2.5 \\
\hline 8 & 0.9 & 0.45 & 0.75 & 90 & 0.8 & 150 & 0 \\
\hline 9 & 0.8 & 0.35 & 0.5 & 77 & 0.6 & 55 & 6.3 \\
\hline 10 & 0.55 & 0.4 & 0.5 & 85 & 0.5 & 35 & 5 \\
\hline 11 & 0.8 & 0.4 & 0.6 & 155 & 0.6 & 120 & 12.7 \\
\hline 12 & 0.8 & 0.5 & 0.55 & 30 & 0.5 & 90 & 0.9 \\
\hline 13 & 0.65 & 0.5 & 0.4 & 47 & 0.4 & 80 & 2.4 \\
\hline 14 & 0.8 & 0.4 & 0.4 & 140 & 0.7 & 100 & 6 \\
\hline 15 & 0.7 & 0.2 & 0.6 & 90 & 0.65 & 40 & 2.45 \\
\hline 16 & 0.75 & 0.3 & 0.5 & 100 & 0.4 & 80 & 5.3 \\
\hline Mean & 0.70 & 0.38 & 0.49 & 95.88 & 0.53 & 90.00 & 4.47 \\
\hline SD & 0.12 & 0.08 & 0.13 & 36.57 & 0.14 & 34.28 & 3.31 \\
\hline
\end{tabular}

$\mathrm{NA}=$ not applicable.

PSA receiving all of the ASA flow. This arrangement may result in a watershed zone on the contralateral dorsal surface of the spinal cord. Given the limitations of our current technique, it is possible that in these asymmetrical cases, finer anastomotic networks between the ASA and the other PSA exist but are not visualized with the injection technique.

\section{Branching Orientation and Anastomosis Between the ASA and PSA}

We identified 3 branching orientations connecting the ASA and PSAs. In the 2 most common scenarios, the ASA was connected to the PSA via bilateral branching arteries, which branched from the ASA at different levels of the conus (Fig. 2A and B). In a more uncommon orientation, the bilateral branching arteries branched simultaneously from the ASA to connect to the paired PSAs. These branching orientations do not appear to have functional significance, but the anatomical description of these branching patterns is novel and has not been previously described.

\section{Conus Medullaris Arteriovenous Malformations and the ABCM}

The ABCM is frequently involved in vascular malformations of the conus medullaris (Figs. 4 and 5). ${ }^{9-12,20,25}$ The angiography provides a robust means of obtaining anatomical information about vasculature at the conus. However, spinal angiography is a rarely performed, timeconsuming procedure that is only performed to evaluate pathological conditions. For this reason we were not able to perform additional correlations between anatomical findings with angiographic data.
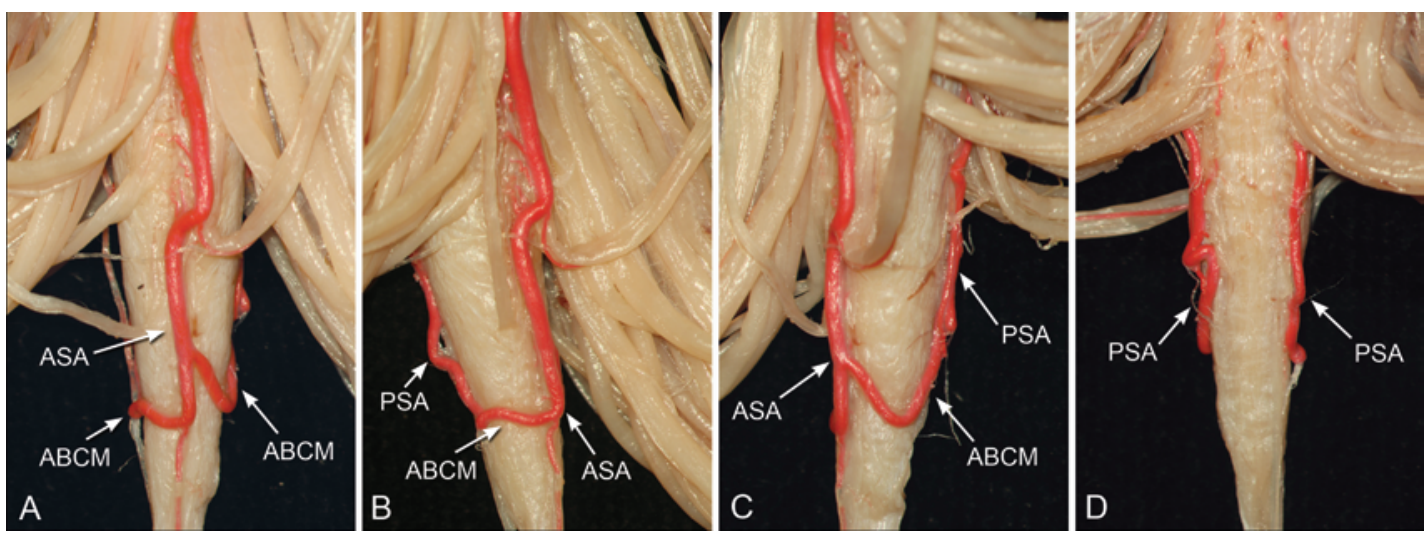

FIG. 1. Gross anatomical specimens. A: Anterior view demonstrating bilateral networks connecting the ASA to the paired PSAs. B and C: Lateral right $(B)$ and left $(C)$ views at the level of the conus medullaris demonstrating the connection of the ASA to the PSAs via the arterial branches of the ABCM. D: Posterior view of the arterial branches of the basket draining into the PSA. 

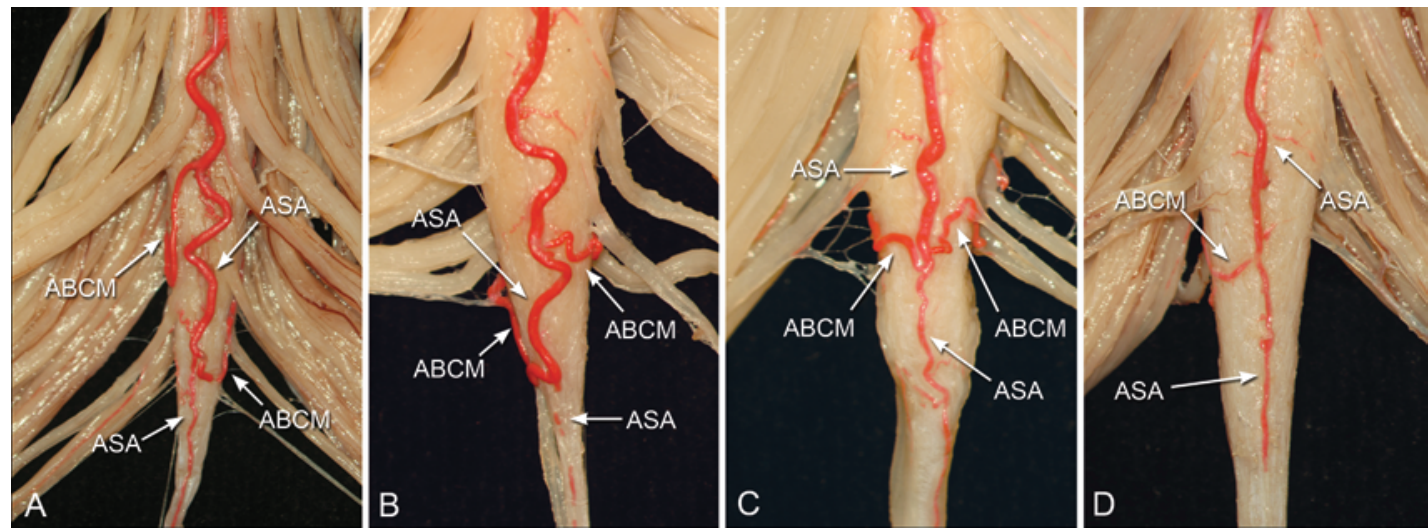

FIG. 2. Anterior gross anatomical specimen at the level of the conus medullaris. $A$ and $B$ : Early right- (A) and left-sided (B) $A B C M$ branching from the ASA. C: Alternatively, ABCM bilateral branches from the ASA may occur simultaneously, although this is a rare arrangement. D: Unilateral right-sided branching from the ASA.
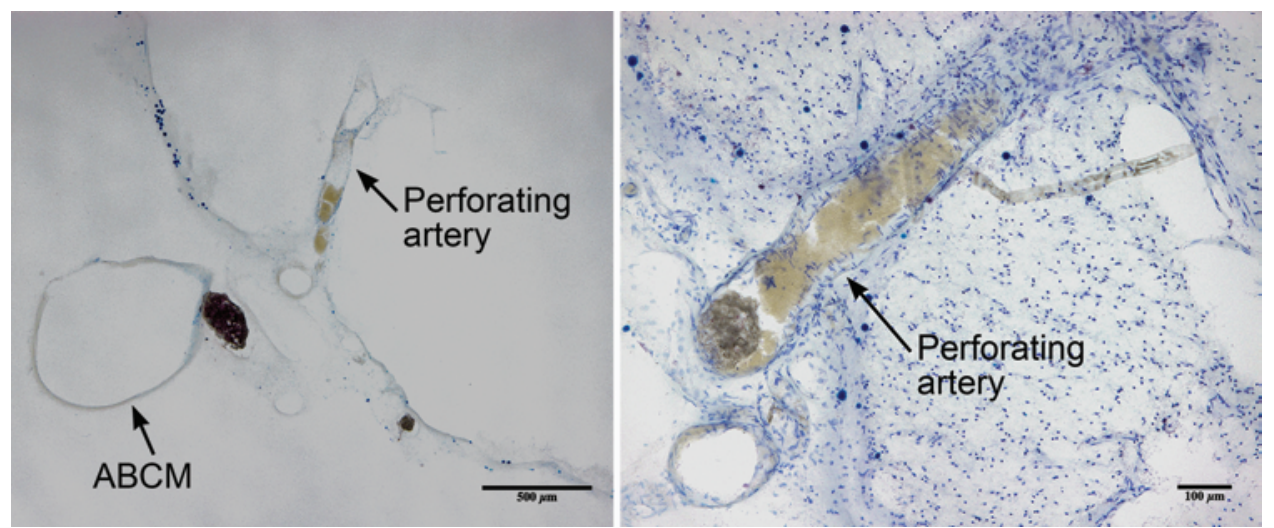

FIG. 3. Nissl stain images. Left: The axial section through the conus medullaris shows a perforator branch arising from the $A B C M$. Right: Small perforator branch of the ABCM surrounded with spinal cord tissue.

We reviewed one of the senior authors' experience (R.F.S.) with resection of arteriovenous malformations (AVMs) of the conus and noted that in complex cases, the $\mathrm{ABCM}$ is ill defined or undefinable on spinal angiogra-
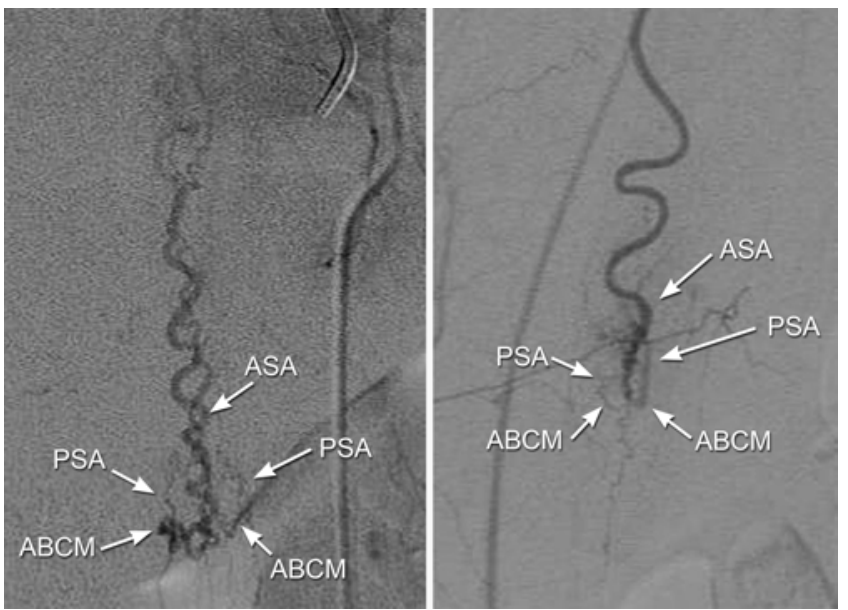

FIG. 4. Anteroposterior angiograms at the level of the conus medullaris demonstrate the involvement of the ABCM in a conus medullaris AVM. The ASA, PSA, and ABCM can be identified. phy. ${ }^{25}$ In many cases of AVMs of the conus, the large size of the nidus obscures proper delineation of the ABCM (Fig. 5).

Understanding of the anatomy of the ABCM and its variations is critical for addressing vascular malformations in this location. The presence of perforating vessels feeding the conus that arise from this ABCM has clinical implications for the resection of vascular lesions as well as other pathologies in this region. This anatomy is often not well described or studied; our study adds a new dimension, highlighting the importance of perforating vessels arising from the $\mathrm{ABCM}$ to the vasculature of the conus medullaris.

\section{Conclusions}

The ABCM is an anastomotic network connecting the ASA and PSAs. We identified 3 different branching patterns connecting the ASA and PSAs. In the majority of the cases, bilateral arteries connected the ASA and PSA, allowing for redundancy in vascular supply to the spinal cord and conus medullaris. Small perforating arteries arising from the ABCM provide blood supply to the conus medullaris tissue. The ABCM is involved in vascular malformations and tumors at the level of the conus. The physi- 


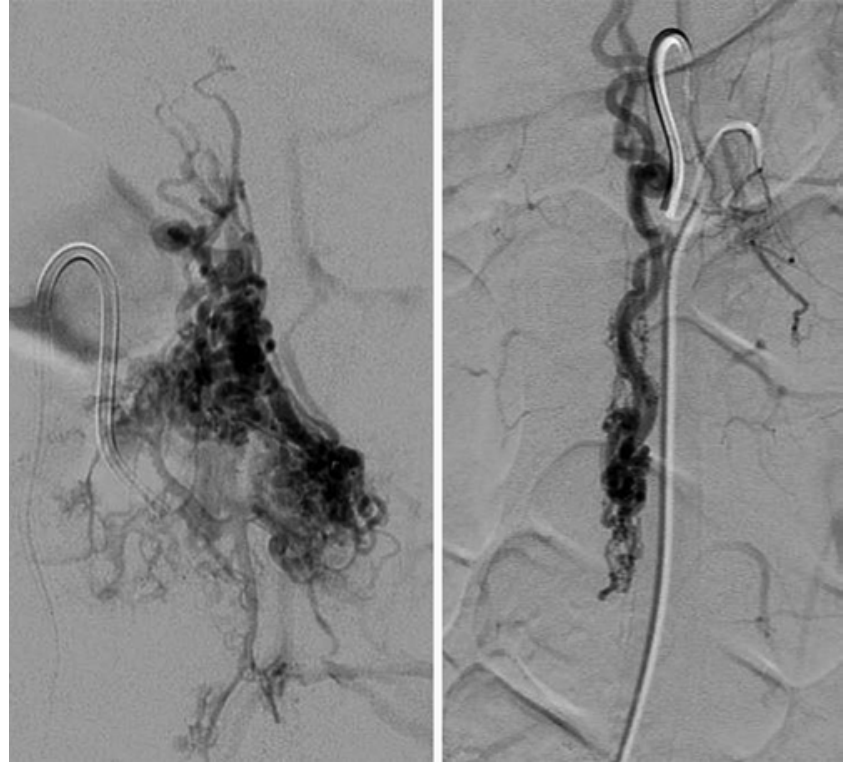

FIG. 5. Anteroposterior angiograms of complex cases of AVMs of the conus medullaris involving the ABCM. The large size of the nidus obscures proper delineation of the ASA, PSA, and ABCM.

ological role of the $\mathrm{ABCM}$ in the vascular malformation of the conus is unclear and requires further investigation. Practitioners treating vascular lesions and tumors of the conus medullaris must have a solid understanding of the anatomy of this critical anastomotic network.

\section{References}

1. Adamkiewicz A: Die Blutgefasse des menschlichen ruckenmarkes II: Theil. die gefasse der ruckenmarksoberflache. S B Heidelberg Akad Wiss 85:101-130, 1882

2. Adamkiewicz A: I. Die Gefasse der Ruckenmarkersubstanz. Sitzungsb Akad Wissench Wien Math-Naturw 84:469, 1881

3. Alleyne CH Jr, Cawley CM, Shengelaia GG, Barrow DL: Microsurgical anatomy of the artery of Adamkiewicz and its segmental artery. J Neurosurg 89:791-795, 1998

4. Altman J, Bayer SA: Development of the Human Spinal Cord: An Interpretation Based on Experimental Studies in Animals. New York: Oxford University Press, 2001

5. Bolton B: The blood supply of the human spinal cord. J Neurol Psychiatry 2:137-148, 1939

6. Djindjian M, Ribeiro A, Ortega E, Gaston A, Poirier J: The normal vascularization of the intradural filum terminale in man. Surg Radiol Anat 10:201-209, 1988

7. Djindjian R: Angiography of the spinal cord. Surg Neurol 2:179-185, 1974

8. Fix AS, Ross JF, Stitzel SR, Switzer RC: Integrated evaluation of central nervous system lesions: stains for neurons, astrocytes, and microglia reveal the spatial and temporal features of MK-801-induced neuronal necrosis in the rat cerebral cortex. Toxicol Pathol 24:291-304, 1996

9. Hsu SW, Rodesch G, Luo CB, Chen YL, Alvarez H, Lasjaunias PL: Concomitant conus medullaris arteriovenous malformation and sacral dural arteriovenous fistula of the filum terminale. Interv Neuroradiol 8:47-53, 2002

10. Kalani MY, Ahmed AS, Martirosyan NL, Cronk K, Moon K, Albuquerque FC, et al: Surgical and endovascular treatment of pediatric spinal arteriovenous malformations. World Neurosurg 78:348-354, 2012

11. Kim LJ, Spetzler RF: Classification and surgical manage- ment of spinal arteriovenous lesions: arteriovenous fistulae and arteriovenous malformations. Neurosurgery 59 (5 Suppl 3):S3-195-S3-201, 2006

12. Krings T, Lasjaunias PL, Hans FJ, Mull M, Nijenhuis RJ, Alvarez $\mathrm{H}$, et al: Imaging in spinal vascular disease. Neuroimaging Clin N Am 17:57-72, 2007

13. Lasjaunias PL, Berenstein A: Surgical Neuroangiography, Volume 3. Functional Vascular Anatomy of Brain, Spinal Cord, and Spine. New York: Springer, 1990

14. Lazorthes G, Gouazé A, Bastide G, Soutoul JH, Zadeh O, Santini JJ: [Arterial vascularization of the lumbar elevation. Study of variations and substitutions.] Rev Neurol (Paris) 114:109-122, $1966(\mathrm{Fr})$

15. Lazorthes G, Gouaze A, Zadeh JO, Santini JJ, Lazorthes Y, Burdin P: Arterial vascularization of the spinal cord. Recent studies of the anastomotic substitution pathways. J Neurosurg 35:253-262, 1971

16. Lazorthes G, Poulhes J, Bastide G, Roulleau J, Chancholle AR: [Arterial vascularization of the spine; anatomic research and applications in pathology of the spinal cord and aorta.] Neurochirurgie 4:3-19, 1958 (Fr)

17. Martirosyan NL, Feuerstein JS, Theodore N, Cavalcanti DD, Spetzler RF, Preul MC: Blood supply and vascular reactivity of the spinal cord under normal and pathological conditions. J Neurosurg Spine 15:238-251, 2011

18. Parke WW, Gammell K, Rothman RH: Arterial vascularization of the cauda equina. J Bone Joint Surg Am 63:53-62, 1981

19. Ross JF, Switzer RC, Poston MR, Lawhorn GT: Distribution of bismuth in the brain after intraperitoneal dosing of bismuth subnitrate in mice: implications for routes of entry of xenobiotic metals into the brain. Brain Res 725:137-154, 1996

20. Spetzler RF, Detwiler PW, Riina HA, Porter RW: Modified classification of spinal cord vascular lesions. J Neurosurg 96 (2 Suppl):145-156, 2002

21. Stein SC, Ommaya AK, Doppman JL, Di Chiro G: Arteriovenous malformation of the cauda equina with arterial supply from branches of the internal iliac arteries. Case report. J Neurosurg 36:649-651, 1972

22. Turnbull IM: Chapter 5. Blood supply of the spinal cord: normal and pathological considerations. Clin Neurosurg 20:56-84, 1973

23. Turnbull IM: Microvasculature of the human spinal cord. J Neurosurg 35:141-147, 1971

24. Tveten L: Spinal cord vascularity. III. The spinal cord arteries in man. Acta Radiol Diagn (Stockh) 17:257-273, 1976

25. Wilson DA, Abla AA, Uschold TD, McDougall CG, Albuquerque FC, Spetzler RF: Multimodality treatment of conus medullaris arteriovenous malformations: 2 decades of experience with combined endovascular and microsurgical treatments. Neurosurgery 71:100-108, 2012

\section{Author Contributions}

Conception and design: Theodore, Martirosyan, Kalani, Preul. Acquisition of data: Martirosyan, Kalani. Analysis and interpretation of data: Theodore, Martirosyan, Kalani, Preul. Drafting the article: Martirosyan, Kalani. Critically revising the article: Theodore, Lemole, Spetzler, Preul. Reviewed submitted version of manuscript: Theodore, Lemole, Spetzler, Preul. Administrative/technical/material support: Theodore, Lemole, Spetzler, Preul. Study supervision: Theodore, Lemole, Spetzler, Preul.

\section{Correspondence}

Nicholas Theodore, c/o Neuroscience Publications, Barrow Neurological Institute, St. Joseph's Hospital and Medical Center, 350 W. Thomas Rd., Phoenix, AZ 85013. email: neuropub@ dignityhealth.org. 